\title{
Challenging power from the bottom up? Community protocols, benefit-sharing, and the challenge of dominant discourses
}

\author{
Louisa Parks \\ University of Trento \\ Forthcoming in Geoforum
}

A group of traditional healers in South Africa talk about how to harvest medicinal plants that grow nearby but behind the fences of protected areas; traditional pastoralists in Greece consider how they their work contributes to their local culture, economy and ecology; villagers in Namibia debate how to protect their knowledge of wildlife stewardship and pass it to future generations; a community association in Malaysia moves to rejuvenate rice farming in a remote area; 33 indigenous communities in Argentina describe how anyone who wishes to access their land should go about asking their permission. These rather different situations are drawn together through the idea of benefit-sharing. How, for example, should the benefits of the plants and animals within protected areas in South Africa and Namibia be shared with communities? How might the benefits of traditional pastoralism be recognised in present day Greece? How should the proceeds from state subsidised rice cultivation feed back into the community in Malaysia? How should extractives companies in Argentina engage with communities and develop ways of working that benefit communities and respect their land (or learn to take no for an answer)? Benefit-sharing, a relatively recent term coined in international law, seeks to deal with such situations. It refers to the idea that indigenous peoples and local communities that protect and sustain natural resources should share in benefits produced on the basis of their knowledge and resources.

In many cases benefit-sharing is nothing but a new label for what has long taken place, albeit under a different name (such as the commons). More recently however, the longstanding goods or benefits that local communities provide have been explicitly recognised as key in the fight to tackle environmental problems. Benefit-sharing and the recognition of the contributions of indigenous peoples and local communities is brought up in a number of international texts ranging from plant genetic resources to human rights and climate change (Morgera, 2016). The best known and developed source of international law and policy on benefit-sharing, however, is the Convention on Biological Diversity (CBD). The fair and equitable sharing of benefits from the use of traditional knowledge held by local communities and indigenous peoples is a central aim of the CBD, and its Nagoya Protocol on Access and Benefit-Sharing (the Nagoya Protocol) contains the most specific rules in existence for benefit-sharing from bioprospecting. Nevertheless, questions about what exactly benefits are and how they should be shared in fair and equitable ways remain unanswered - even in the Nagoya Protocol (Morgera, 2016).

One way of addressing these questions is through community protocols - documents developed by local communities to record, among other things, information on their practices, institutions, customary law, rights and visions of development. Community protocols have attracted attention 
among policymakers (Jukic and Collings, 2013) as well as scholars and practitioners of international law (for example Bavikatte, 2014; Bavikatte et al., 2015; Jonas et. al., 2010; Tobin, 2013). ${ }^{1}$ The Nagoya Protocol explicitly recognised community protocols following the efforts of representatives of indigenous peoples and local communities. Inspired by work by, among others, Darrell Posey (2004), community protocols seek to help uphold the rights of indigenous peoples and other communities by filling a space at the nexus of international, national and customary law and policy. They are based on processes that aim to allow communities to act both defensively, codifying existing practices and underlining their rights, as well as proactively, by outlining future visions (Jonas et al., 2010). Following Bavikatte et al. (2015), a community protocol:

is a convivial legal tool that is collectively developed by a community. It is aimed at those who want to engage the community and it seeks to articulate the community's way of life, history, customs, and decision-making processes. It begins a dialogue that goes beyond a purely instrumentalist or use-value interaction and embarks on building a relationship. Through its community protocol, a community says to the listener: if you want to access our lands, biodiversity, and knowledge, then you need to hear our story, you need to understand what these things mean to us, what our values are, and how we make decisions. (Bavikatte et al.: 20)

Bavikatte et al. (2015) focus on community protocols as legal tools, yet their definition moves beyond legal relations to encompass questions about how social actors interact. Other socio-legal authors have discussed community protocols and benefit-sharing from the perspective of legal pluralism in depth. Tobin (2013) outlines the need for the respect and recognition of customary law for the protection of indigenous peoples' knowledge and resource rights, and explores the obstacles and possibilities for this in different arenas. Regarding community protocols and legal pluralism, he finds that the 'adoption of such protocols would have the potential to significantly influence the design of national, regional and international law and policy' (Tobin, 2013: 159). Vermeylen (2013) points to the difficulties encountered at regional and national levels when legal pluralism comes to be practiced, underlining the rigidity of some legal systems with regards to oral histories as evidence and collectively held knowledge for example. Yet to imagine how legal pluralism might be achieved through community protocols requires more attention to be paid to how these documents act within social relations of power - how exactly might community protocols convey what Bakivatte et al. (2015) call a community's 'space within' to become 'convivial legal tools'? If they are tools for starting dialogues, community protocols must to some extent translate the customary law as well as the worldviews of communities to all the external actors that engage with them. As de Sousa Santos (2015) argues, existing institutions view the knowledge held by indigenous peoples and local communities as superstitions and thus not to be counted, necessitating the kind of 'intercultural translation' that community protocols might to provide.

To discuss the possibilities of community protocols in these terms, this article aims to bring together insights from several bodies of literature through a political sociological lens of power. A focus on how community protocols might address the power relations that exist at the local, international and national levels brings to light issues that should be considered in the processes communities follow to produce protocols to make them effective. To better conceptualise power, the work of Steven Lukes (2004) is useful. Lukes (2004) outlines three dimensions of power: the visible, the hidden and the invisible. The first points to clear arenas of power in a society - such as a parliament. The second

\footnotetext{
${ }^{1}$ Further publications on community protocols can be found at http://www.communityprotocols.org/toolkit/additional-resources/publications/books-booklets accessed 1 December 2016.
} 
concerns agenda-setting power and the power to define key actors in a debate. Finally, the third dimension is the most insidious form. Invisible power is exercised within individuals' minds, defining what is right, possible and believable. This form of power is exercised through self-discipline socialising discourses are internalised by individuals and delimit their outlooks. It is this dimension of power that the article seeks to discuss with a view to how it might be challenged by community protocols. While the existing literature touched on briefly here is thorough in discussing the potential of community protocols to contribute to international, national and local processes in terms of promoting legal pluralism, there is no explicit discussion of the 'invisible' discursive power relations that need to be challenged if community protocols are to mount their most effective defence of communities' worldviews or 'spaces within' (Bavikatte et al., 2015).

Powerful discourses about environmental conservation and human rights - central elements in community protocols - are discussed in political ecology. Political ecology is a broad school, bringing together disciplines including geography, politics, socio-legal studies, political sociology and others. As the focus of this article is firmly on power, and due to the limits of the author, the emphasis here is on politics, political sociology and socio-legal literature discussing aspects of benefit-sharing: though the relevance of geography is clear, work from this discipline is only drawn on in a limited manner. What this literature communicates about invisible power and environmental protection is that a number of hegemonic discourses shape the outlooks of many groups and actors about how environmental protection should be achieved. By shaping outlooks, these discourses exclude others, such as those held by some local communities recognised as stewards of the environment. Their discourses, many scholars argue, are characterised by more inclusive views of the world that do not separate 'nature' from the community, but rather understand peoples' reciprocal relations with the earth to form part of a single community (Bavikatte, 2014; Bavikatte et al., 2015; Vermeylen, 2017). The dominant discourses, on the other hand, do not conceptualise the earth and people as part of a single community. The picture is a complex one, but an overview of this literature shows consensus on an overarching discourse about colonialism and capitalism (Bavikatte, 2014; Svarstad, 2004), with linked discourses around the separation of humans from 'nature' (Uggla, 2009), and the need for outside actors to impose solutions on different groups (Bixler et al., 2015; Nelson, 2010). These dominant discourses shape environmental policies at different levels, including the international, and are applied without attention to how local groups steward the environment. Despite statements recognising the importance of local groups in the fight to protect the environment, the argument goes, policies remain based on dominant discourses that threaten the very local groups they aim to protect.

There is some disagreement among scholars of benefit-sharing on this: some scholars argue that spaces for local voices and approaches at the international level exist within the CBD (Bavikatte et al., 2015; Reimerson, 2013). The aim of this article is thus to begin to investigate how community protocols face up to the different discourses that are argued to shape environmental policy at the international, national and local levels, and thus how they might help communities achieve fair and equitable benefit-sharing. The focus for the international level is the CBD - the most developed international regime for benefit-sharing as well as that argued to be the most open to representatives of indigenous peoples and local communities (Affolder, 2017). The basis for discussions of national and local levels is a series of five original case studies carried out in Greece, South Africa, Argentina, Namibia and Malaysia. These case studies do not seek to represent the realities lived by these communities or to speak for them. Rather, they aim to connect local experiences of benefit-sharing including those outside the scope of the Nagoya Protocol - with international processes (Author). ${ }^{2}$ In

\footnotetext{
${ }^{2}$ Reference to project blinded for peer review.
} 
comparing the cases, a number of common issue areas that speak to how community protocols might be most effective in challenging powerful discourses arise. The contribution of the article is thus to open up discussions about what conditions might be needed for community protocols to fulfil the role they have been attributed as challengers of the discourses that guide environmental policy.

The approach is as follows. First, the five case studies are introduced, and the methodology and methods described. A review of the literature on benefit-sharing and related issues follows to give a better illustration of the powerful discourses local communities are argued to be facing. Next, a discussion session illustrates the ways in which community protocols might challenge these discourses. The discussion also introduces the common issue areas that arise from the comparison of the case studies. Finally, the conclusions reflect further on these common issue areas and suggest avenues for future research.

\section{Community case studies: discussions of benefits, sharing, and community protocols}

The five case studies drawn on here were undertaken within a wider project on fair and equitable benefit-sharing, which includes a focus on how this concept plays out in different local contexts. As community protocols are linked to achieving benefit-sharing for communities, discussions about protocols were used as an indicator of a community being interested in some form of benefit-sharing. The cases were also picked to provide as much variation as possible: they cover different political and legal contexts, different stages of discussions around benefit-sharing and the possibility of working towards a community protocol, and different natural resources. This variation is intended to increase the validity of the findings: if common issues appear to affect discussions about benefit-sharing across such different contexts and stages of discussions, they may be more generally applicable and inform benefit-sharing policies across the board. The cases also concern communities formed for different reasons: working together because of location and shared identity (Argentina, Namibia, Malaysia), or because of a shared profession and location (Greece and South Africa).

A five case comparison was also chosen because there is relatively little comparative case study work in this area (but see Adger et al., 2001). A wealth of literature examines the ways that local communities steward natural resources (Nelson, 2010), and the issues local communities face at the international level (Reimerson, 2013; Marion Suiseeya, 2014). By studying five cases with a similar methodology and as much variation as possible, the aim was to make findings about any common issues more robust. The choice to study five cases necessarily involved some trade off in terms of depth. To seek to counter this, partner organisations were worked with. This decision carries impact, as the choices and views of the cases are to some extent filtered and framed by the those organisations. For this reason, all of the partner organisations were chosen because they had been working with communities in long-term relationships. ${ }^{3}$ The long-term nature of these relationships also allowed some reflexivity in the research, where legal scholars in the project were able to tailor some work to issues raised by communities. In addition, each case study location (with the exception

\footnotetext{
${ }^{3}$ The partner organisations involved in the project were: Natural Justice in Namibia, South Africa and Malaysia; Foundation for the Environment and Natural Resources (FARN) in Argentina; and the Ikarian Documentation and Research Center in Greece.
} 
of Namibia) was visited twice over two years to capture developments over time and allow for feedback to participants where requested.

The methodology was designed to capture local experiences of issues linked to the concept of benefitsharing as defined in international environmental law. As mentioned, the cases are part of a wider project including research on how benefit-sharing as a new norm or discourse in international law translates at local levels, and in turn how local communities feed evolving understandings at the international level (without assuming that diffusion occurs in that order). The aim of the project is 'to reflect on the stage at which fair and equitable benefit-sharing finds itself, and thus on its strength as a legal norm capable of changing behaviour' (Author 2015: 365). A necessary step is to consider how local communities challenge existing powerful discourses and ensure fair and equitable benefitsharing. The methodology adopts an interdisciplinary approach drawing on insights about power, discourse and norm diffusion from law, political sociology and international relations (Author, 2015). In conducting the case studies, information about how the community perceived benefit-sharing was gathered by paying attention to the community's aims, ideas of benefits, modes of organising, and perceived issues in relations with external actors as well as within the community. This was supplemented with literature about the political and legal contexts of each community, and current affairs. The methods for collecting data varied, but included participant observation of community meetings, group and individual semi-structured interviews and unstructured conversations with community members, NGO representatives, local, regional and national authority representatives, and academic experts. ${ }^{4}$

The Greek case study concerns Ikaria, an island in the north-east Aegean. Ikaria's traditional goat pastoralists began to discuss the possibility of a community protocol as they felt their role was misunderstood by others and that they were generally excluded from decision-making processes affecting their livelihoods, a situation exacerbated by the fact that they had no functioning association. The pastoralists were concerned about access to land for grazing and securing a local slaughterhouse to allow them to sell meat and keep animal numbers at the right level. Pastoralists have traditionally played an important economic and cultural role on the island, providing food, identifying and keeping water sources clear and contributing to prevent and manage forest fires. Pastoralists thus have access to various types of land (both private and public) considered as the island's commons. Access to land is now becoming a contentious issue due to a complex variety of interlinked issues in a context of European Union (EU) membership. EU laws have changed traditional market access routes with rules on slaughter and transport. This, along with older rules on subsidies, contributed to a rise in the goat population, threatening the island's delicate ecosystem, hence the need for a local slaughterhouse. Questions around access to land have arisen in this context, as well as general confusion about land ownership and use that has come to the fore in the context of the Greek experience of the global financial crisis. In particular, the national government is thought to have an interest in land on the

\footnotetext{
${ }^{4}$ In Greece 9 semi-structured and 1 group interview were carried out with pastoralists and key informants (for all cases these included NGO representatives, lawyers, forestry and protected area managers, local, regional and national government representatives, and academic experts). In Malaysia informal interviews were held with 12 local community members fulfilling a range of roles in addition to informal conversations with other community members. In Argentina 14 semi-structured interviews were carried out with community members and key informants, in addition to partial observation of a community meeting and 1 group interview with community members. In Namibia, a total of 5 community meetings were observed in addition to 2 semistructured interviews and informal conversations. In South Africa two community meetings (lasting 2 days each) were observed and 6 semi-structured interviews held with key informants. For all cases these activities were carried out over two trips at a distance of circa 2 years between 2014 and 2017, with the exception of Namibia.
} 
island for a wind farm. At the time of writing, there is little clarity about how the pastoralists might proceed and no community protocol is in place.

The Malaysian case focuses on the Kelabit community from Bario and its surrounding villages in the highlands of Sarawak, Borneo. An aging population and rising social mobility have contributed to labour shortages, which in turn left cultivation levels of the unique Bario rice variety critical, threatening both the variety of rice and food security. A highly respected association of Kelabit community members, for the most part living away from Bario, decided to tackle the problem by bringing in a farming company to take over agricultural labour where needed. They secured subsidies from the Sarawak government to establish a tri-partite management deal between the local association, the state government and a commercial farming company to grow the rice and provide machinery, access roads and improved irrigation. Cultivation levels have risen with the project's implementation, yet the scheme has seen some community members raise questions around traditional and industrial farming techniques as well as around the use of different rice varieties and other arrangements. The possibility of a future community protocol has been discussed but is not currently underway. The principle wish for those farmers that question some of the techniques used by the farming company - which is not the case for all farmers in the areas - is for the farming company to listen to and act on the issues they raise.

The Argentina case concerns 33 indigenous communities resident around the salt planes of Salinas Grandes and Laguna de Guallatayoc in the Andes, close to the borders with Chile and Bolivia. Mining companies have been interested in the indigenous salt planes since the discovery of lithium, needed for batteries in a range of electronic goods including cars. The 33 communities were concerned that mining permits were assigned without proper consultation, and without sufficient consideration for negative impacts on scarce water resources in the area. Since Argentina is a party to Convention 169 of the International Labour Organisation concerning free, prior and informed consent, which has also been applied under the American Convention on Human Rights, the communities felt they had a good legal basis to bring a complaint to the Inter-American Commission on Human Rights. Faced with this situation as well as other perceived threats to their lands, the communities also drafted a community protocol detailing consultation and consent procedures with reference to the community's worldview and the natural salt cycle, as well as international, national and regional law and the community's history (Comunidades indígenas de las Salinas Grandes y Laguna de Guayatayoc de Jujuy y Salta, 2015). The community protocol had led to the suspension of mining permits in the area of the 33 communities at the time of writing, and a provincial law that would oblige external actors to respect community protocols was under consideration in Jujuy where most of the communities are located.

The Namibian case focuses on cultural reproduction and the wildlife stewardship skills and traditional knowledge of Khwe residents of Bwabwata national park. Historically, this group hunted and gathered food in what is now a core wildlife protection area of the park. Without access and without the level of recognition they feel necessary from the government - including for their residence within a national park, the Khwe communities fear that their traditional knowledge may disappear, in particular because they feel it is already less widespread within their community. They have begun drafting a community protocol with support from the Namibian ministry of environment and tourism to ask for more government recognition and to support their claim to access and to cultural reproduction. Their efforts are also tied to their involvement in the Kyaramacan Association, which aids in park management, controls hunting concessions and implements a benefit-sharing agreement for the economic proceeds of hunting concessions as well as meat, devil's claw harvesting and sale, and jobs (on this community see also Koot et al., 2016). At the time of writing, the group had 
completed drafting their community protocol, and hoped to launch it since the Namibian government had recently passed its Access and Benefit-sharing Bill.

The South African case is a well documented one (Bavikatte et al., 2015; Delgado, 2016; Sibuye et al., 2012), and concerns a group of traditional health practitioners from a range of ethnic and linguistic backgrounds. This group formed the Kukula traditional health practitioners' Association and drafted a community protocol in 2009 (Traditional Health Practitioners of Bushbuckridge, 2010) to highlight their work in communities and threats to biodiversity in the area, adjacent to Kruger national park. The practitioners are concerned about access to medicinal plants, often only available within protected areas, and the preservation of cultural heritage (Sibuye et al., 2012). At the time of writing, the Kukula Association members were discussing how to renew their community protocol to reflect their current status and needs. Since the original protocol was written, the Association has become more focused on gaining recognition from local traditional authorities, on acquiring land, and on negotiating access to protected areas. The Association has made progress on these points in a legal and political context that is explicit about benefit-sharing and rights over traditional knowledge. Nevertheless, these efforts are taking place within a complex situation featuring a continuing rhino poaching crisis and land claims from the apartheid era.

\section{Political ecology, global environmental governance and its local effects}

The aim of the article is to consider the different ways that communities' community protocols challenge dominant discourses of power linked to environmental policy. This section provides a brief overview of literature that broadly fits under the rubric of political ecology to illustrate these dominant discourses. The review is far from exhaustive, and draws on literature linked to issues around benefitsharing.

Political ecology seeks to understand the ways in which people and societies interact with natural resources as embedded within power-laden discourses. These powerful discourses exclude some ideas and explanations as a result of promoting others. The dominant discourses argued to affect environmental governance in much work on political ecology are colonialism and capitalism. Linking this to benefit-sharing, Mulligan's (1999) work on the CBD describes this as firmly rooted in a colonial discourse where raw materials from the global South are processed into expensive products in the global North. Adger et al. (2001) also touch on the continued importance of colonial views in their analysis of bioprospecting in the CBD as a 'win-win' discourse as opposed to a critical view of biopiracy, where the colonial model of exploitation is repeated. Their work also evidences the close link between colonialist discourses and capitalist discourses, often used interchangeably since colonial expansion was driven by the search for further profit. Bioprospecting is traced to colonial searches for useful plants, with the export of plant material underpinning colonial and economic expansion and continuing in the North-South exchange described above (biopiracy). ${ }^{5}$ The similarities between colonial and capitalist discourses are also discussed in work on the valorisation of nature, that is the idea of assigning monetary value to environmental resources. Wilkinson (2014) explores payments for ecosystem services through an eco-feminist framework, and finds that the underlying problem of attaching economic worth to 'nature' is that resulting schemes are underpinned by a discourse that threatens the system that produced the 'good' (such as sustainable forest use or the production of

${ }^{5}$ On this see also: Parry (2004); Van Dooren (2008); Oguamanam (2012); Robinson (2010); and Shiva (1997). 
useful traditional knowledge) sought in the first place. A large part of the problem, she argues, is the narrow definition of what is valuable as that which makes economic profit. What this definition excludes is often work that is fundamental to conservation goals (Wilkinson, 2014; Castree, 2008). Benefit-sharing agreements for bioprospecting are also discussed as payments in return for knowledge and plant material. Here too, defining communities who provide plants and knowledge is crucial, and problematic where private actors seek out communities (or individuals within them) on the basis of ease of access and avoidance of controversy (Hayden, 2003; Greene, 2004).

Literature discussing global environmental policies also underlines that many problems flow from external imposition - policies are applied without consideration for local specificities. The focus in much of this work is at the local level. Vermeylen (2007) looks at issues arising following the conclusion of a benefit-sharing agreement on Hoodia for dispersed San communities. The creation of institutions that did not reflect the breadth of this community caused various issues, not least ineffective communication about the agreement to all community members. Literature focusing on experiences of community-based natural resource management shows similar findings across a range of cases. The link to colonial discourses often arises here as well, as models of fortress conservation are attributed to colonialists equating indigenous peoples with 'wild' nature, thus removing their agency in shaping landscapes and justifying their removal (Jones, 2006). Poor policy decisions also stem from external imposition: though fortress conservation models have increasingly given way to participatory approaches, their origins in this discourse can translate into, for example, corruption and a lack of real power transfer (Jones, 2006). Bixler et al. (2015) provide recent comparative examples of difficulties in local level benefit-sharing and conservation schemes linked to power and capacity asymmetries silencing minority voices. The findings from work at the local level thus underline the various problems emanating from solutions imposed by external actors with colonial/capitalist understandings of the world that do not take sufficient account of local specificities.

Work considering the availability of spaces for local voices at the global level is also pertinent. Reimerson (2013) considers the echoes of a colonial discourse in the CBD in this line, arguing that the text of the CBD perpetuates colonial discourses that limit the scope of local and indigenous groups to draw on the treaty to protect themselves. She notes a particular element of colonial discourse linked to the othering of local communities and indigenous peoples to be present in the CBD. Colonial forces not only othered nature, allowing it to be defined as wilderness to be tamed, but also othered residents, denying their agency in shaping lands and waters (as noted above). Colonial discourse thus includes a 'nature-culture dichotomy' linked to the distinction made between nature and the role of humankind in its management. Although Reimerson deems this discourse to be 'less apparent' in the $\mathrm{CBD}$, leaving some room for the agency of local communities and indigenous peoples (Reimerson, 2013: 1005), the nature-culture divide as a consequence of underlying capitalist-colonial discourses shaping laws and policy is another common theme in the literature (Castree, 2008). Broad observations about the consequences of the definition of what is 'natural' and how this is understood as separate from 'culture' are provided by Uggla (2009), who argues that the CBD is unique in its recognition of the intrinsic value of biodiversity and the various meanings of nature (found in the preamble), which may allow holistic approaches combining environmental protection with human rights to proceed more easily.

The idea that the CBD allows spaces for other worldviews that do not define nature as something to be exploited is echoed by other scholars (including Escobar, 1998 with reference to Article 8(j)). Jonas et al. (2010) and Bavikatte (2014) discuss this in detail, and link this possible discursive space to community protocols. Bavikatte (2014) writes that local and indigenous communities must contend with bodies of law that reify hegemonic, capitalist discourses, and place a Lockean conception of 
private property (i.e. private property as exclusive access) at the centre of legal regimes. One of the most prominent examples challenging this discourse, he argues, is what was achieved by the representatives of local communities and indigenous peoples in the negotiation of the Nagoya Protocol. By recognising community protocols, the Nagoya Protocol leaves space for a wider interpretation of property based on understandings of the world that lie outside the nature/culture dichotomy, and thus challenges practices arising from dominant discourses. Community protocols are seen as an opportunity that 'empowers communities to challenge the fragmentary nature of state law, and instead to engage with if from a more nuanced and integrated perspective' (Bavikatte, 2014: 234; Tobin, 2013; Bavikatte et al., 2015). Yet other scholars dispute this view of the CBD: Marion Suiseeya's (2014) work, based on a collective ethnography at multilateral negotiations on the implementation of the Nagoya Protocol, suggests that they were dominated by debates over instruments which severely limited space for negotiating fundamental meanings of nature and culture. Brand and Vadrot (2013) argue that epistemic selectivities in the CBD impose limitations about which arguments are admissible, excluding, for example, traditional knowledge outside the requirements of the Nagoya Protocol. In another perspective, Tobin (2013) argues that the EU's regulation designed to implement the Nagoya Protocol threatens to undermine it entirely by a return to biopiracy, demonstrating that whatever space might be available for minority discourses at the international level can soon be eroded by rules adopted by states or regional international organisations. A related point made for example by Wynberg and Laird (2016) is that policy processes in the CBD are ill-fitted to keep apace with technological developments, as indeed are most national governments, which may again erode the usefulness of the Nagoya protocol. Robinson (2015) provides in-depth discussions of a range of benefit-sharing agreements and their compliance with the Nagoya protocol, underlining the wide variations of contexts in which agreements must fit and the difficulties in achieving this.

This brief review suggests a number of clear themes that are also reflected in the wider literature. The acknowledgement of the power of discourse is a common trait in line Lukes (2004), where dominant discourses are seen to exercise power by shaping worldviews and thus the limits of what may be considered rational solutions to environmental problems. The dominant discourses identified are rooted in capitalism and colonialism. In this reading, colonial powers in the global North exploited the raw materials of the global South for capitalist gain, and these relations are perpetuated in the present, including through the solutions proposed for global environmental problems. These are described as externally imposed and misguided in seeking to assign economic value to nature as distinct from society or culture. This dichotomous perspective is not present in the worldviews of many of the indigenous peoples and local communities that have in recent years been recognised as key to environmental protection and conservation (Vermeylen, 2017). Because of this mismatch, current policies are argued to threaten the societal systems that produce the goods they aim to protect. Some scholars see the CBD as hosting spaces for resistance, and community protocols as allowing a direct challenge from the local level (Bavikatte, 2014). Others challenge this view, seeing little effective space in the global arena of the CBD (Marion Suiseeya, 2014).

\section{Community protocols and spaces for local voices}

How might local communities draw on community protocols to challenge the discourses argued to dominate environmental policy? Here, the cases are used to illustrate reflections on this question. Each of the major discourses identified in the short review is taken in turn, with the international, national and local levels considered for each. 
Capitalist and colonial discourses are linked in the literature reviewed, which sees colonial practices as an outgrowth of capitalism and investigates how this may provide a key to global environmental policies. Space for alternative discourses is argued to be available at the international level within the CBD however, and community protocols are proposed as a way of accessing that space (Bavikatte, 2014). One potential curb on the potential of community protocols to challenge this dominant discourse is that they are recognised in the Nagoya Protocol. As discussed above, the recognition of community protocols here has been seen either as a victory creating spaces for non-dominant voices, or conversely as an attempt to co-opt local voices into the colonialist North/South relations attributed by many to access and benefit-sharing (ABS) at the international level (Mulligan, 1999. In this sense, how far a community protocol could really challenge the discourses that underpin ABS may seem limited in a reading that sees the mechanism as a purely capitalist exchange. Morgera (2016), however, underlines that benefit-sharing is not a precisely defined legal concept, and that the concept thus has the potential to be used as a tool to underpin dialogues between worldviews beyond simple utilitarian exchanges. In this sense, the potential of community protocols to address capitalist discourses at the international level may be exactly to demonstrate the range of ways in which local communities define benefit beyond (though not necessarily excluding) monetary benefits.

The case studies underline how communities conceive of benefits in a variety of ways. They also underline that defining benefit-sharing and benefits in monetary terms is something debated beyond the realm of ABS. One common theme emerging from the cases in this regard is the definition of recognition either as a benefit, or a precondition necessary to receiving other desired benefits. This preoccupation alongside the variety of benefits sought shows awareness among the local communities about the need to challenge colonialist/capitalist discourses that define benefit in terms of money or other goods given in simple exchange. In the Greek case, pastoralists defined their problems in terms of being misunderstood and their contributions forgotten. Their animals graze away undergrowth crucial to preventing forest fires, and keep certain plants at bay to boost the biodiversity of the island for example. Thus, the material benefits they sought (including a local slaughterhouse) were accessible only if pastoralists' contributions were first recognised and set off against the disadvantages attributed to the slaughterhouse. In the Namibian case, benefits were tied to questions of cultural reproduction. The community members worried that without access to particular areas their knowledge would continue to decline, and rob future generations of their access to it. In Malaysia the farming techniques questioned by some were seen as linked to a need to include traditional farming methods in the agricultural agreement - for example by respecting the natural calendars of the area when planting and harvesting - and to improve communication, rather than being dominated by the desire to increase productivity. In Argentina the failure to follow rules about environmental impact assessments was partly attributed to the perception that the state had not recognised that land belonged to communities as promised. This lack of recognition of the communities provided an explanation for the failure to follow rules about an environmental impact assessment. By outlining different understandings of benefits and pointing to the need for real recognition as a precondition for the worldviews of communities to be taken seriously, community protocols may thus challenge prevailing capitalist/colonialist discourses.

Another potential limitation to challenging the colonialist/capitalist discourse at the international level is the CBD's recognition, in line with a predominant ideal in international law more generally, of state sovereignty over natural resources (Reimerson, 2014). This highlights that while community protocols can address issues dealt with in global arenas, they must primarily address a range of national actors to challenge dominant discourses. The potential for community protocols in this regard necessarily 
varies between states as well as peoples or communities, and no comprehensive conclusion is possible. Yet it is clear that colonialist/capitalist discourse matters if we consider that an important factor in state opening to minority discourses is likely to be the economic worth of the natural resource in question (Nelson, 2010). The Argentinian case is a good illustration - lithium was named by both the federal government in place in 2015 and the province of Jujuy as a 'strategic resource' for the country. This was another factor in the perceived failure to follow rules on impact assessments, along with confusion over the application of the law (rules for mining and environmental law appear to contradict one another). In the Greek case, local pastoralists feared that their access to land may suffer in part due to the central government in Athens seeking to secure land to build a wind farm, in turn in response to the pressure to raise funds imposed by the EU. In Malaysia, the good relationship between the community in Bario and relevant government bodies helped secure state subsidies for the agricultural deal. How far community protocol might address capitalist/colonialist discourse in national contexts thus depends on a number of factors including the economic worth of the natural resource (where money is at stake, challenging the capitalist discourse will be more difficult) and legal and political landscapes (which will furnish varying opportunities to be heard). The need to challenge dominant discourses at different levels is clear: challenging and speaking to the international level may be crucial for communities in national contexts that do not provide much space for their voices. For the cases here, those with a community protocol in place (Argentina and South Africa) saw the most results in terms of addressing state actors: in Argentina the provincial government halted mining permits, while in South Africa the traditional healers are in contact with a number of actors and have been invited to take part in various projects.

Another point for consideration is suggested by research on community-based management as well as the case studies. This concerns the importance of the processes leading to the negotiation of community protocols as opportunities to ensure that questions of recognition are also considered within communities. In other words, community protocols need to be understood as long-term processes, not short-term 'events'. The processes of community protocol negotiation are essential for a meaningful challenge to a dominant discourse -if a protocol does not reflect a consensus built by and shared by a whole community, its message loses real meaning for that community and any challenge to a dominant discourse is subsequently meaningless. This idea can be expressed in its more extreme form with the idea of elite capture, where consent is secured from a single or small number of community members, often in exchange for payment. This is clearly linked to capitalist dominant discourses and is a well-documented feature in cases where benefit-sharing has not worked to plan (Nelson, 2010; Wynberg and Hauck, 2014). The case studies show the importance of how a community organises in this sense. In the South African case study, the members of the community of the Kukula Association joined together to draft a community protocol on the basis of shared interests, but span different ethnic and language groups. Because the group had to be built from scratch as a community, particular attention was paid to consensus building, credited for the perceived success of their community protocol (Sibuye et al., 2012). Similarly, the 33 communities in Argentina case also paid attention to achieving consensus: 'In our community life we are used to carrying out different tasks in the form of "minka", work shared between us all, putting together the efforts of all of us for the benefit of the community or of one of its members. So we drew up this document in this way, in a communal and shared way, finding consensus between all the players in our communities, discussing each concept and each word' (Comunidades indígenas de las Salinas Grandes y Laguna de Guayatayoc de Jujuy y Salta, 2015: 5). ${ }^{6}$ In comparison to other cases those with community protocols in place had paid more attention paid to organisation. Other cases where less attention was paid to organisation have seen fewer outcomes so far. In the Malaysian case, local farming practices and values were not considered before the conclusion of the farming agreement, leading to a host of issues

\footnotetext{
${ }^{6}$ All citations translated from the original Spanish.
} 
being raised. The Greek case, where pastoralists do not have a functioning association and where the path forward is unclear, also underlines this point. In order for community protocols to address powerful discourses outside communities they must be authentic, and this mean paying attention to process and organisation. Recognition is thus key not only to challenging discourses at the international and national levels, but also within communities.

\section{The nature/culture divide and spaces for other worldviews}

The 'nature/culture divide' is framed as a consequence of capitalist/colonialist discourses, and similar considerations arise about how to challenge it. Expansion and growth are argued to lie at the heart of the capitalist/colonialist discourse, resulting in a dichotomous understanding of 'nature' as separate from humankind. Humans can then dominate nature, placing it in the service of economic production (but see Castree, 2008 for a more nuanced discussion). This line of argument also extends in the view of many scholars to the consignment of indigenous peoples to 'nature', placing them under the governance of others for the convenience of economic growth (Reimerson, 2014). Since dominant discourses displace others, a consequence of the centrality of this anthropocentric and dichotomous view is the exclusion of more holistic discourses or worldviews. This is seen to be clear in green economy approaches. ABS is one example, while another prominent is payments for ecosystems services that quite literally put a price tag on nature. Again, there are two possible interpretations. In a more pessimistic view, policies that distinguish nature and humans face an ontological clash when applied in contexts that do not conform to those worldviews. Thus, the very traditional knowledge and practices that the CBD seeks to protect and reward are threatened by these approaches, because they may alter the underlying logics of their reproduction. In a different view, work on ecosystems approaches sees the valorisation of nature as necessary (though not unproblematic) for dominant approaches to accommodate holistic views. By treating ecosystems as a whole, these approaches leave space for a meeting of worldviews (Morgera and Savaresi, 2013; Sikor, 2014). In support of this, the $\mathrm{CBD}$ is seen to be more sensitive to other worldviews, acknowledging the intrinsic value of nature in its preamble, for example.

These contrasting interpretations represent different scenarios for community protocols and their potential for challenging this discourse: the more pessimistic scenario foresees cultural domination, while the more optimistic view suggests there may be space to bring worldviews into dialogue, if not to overcome dominant discourses per se. The case studies suggest that both scenarios are possible, even within the same case. In the Namibian case, a functioning benefit-sharing agreement is in place and the community receives various benefits. Yet one reason behind the community protocol process was concern over cultural reproduction - the skills valued for the management of the park in the benefit-sharing agreement are at risk of disappearing if they cannot be passed on. The successes of the benefit-sharing scheme thus appears finite: where systems of belief, institutions and accompanying ways of life have suffered long histories of marginalisation, this raises questions about how policies based in hegemonic worldviews really destabilise these systems over time. Work in this line has shown that the attitudes and wishes of communities subject to such policies change over time as individuals are socialised into different worldviews, paradoxically placing environmental protection aims at risk (Bayrak et al., 2013). This is also indicated to some extent in the Greek case, where pastoralists and residents in Ikaria expressed the opinion that their worldviews adhered to a longstanding tradition,, which those that had moved to live elsewhere (though still with the power to impact decision-making) no longer understood.

The worth of community protocols as expressions of alternative worldviews is thus clear. Expressing a worldview may for dialogue between dominant and minority worldviews, and may also allow a 
community to rediscover or (re)define worldviews at risk of disappearing. Longstanding marginalisation may be a factor in the latter, including structural inequalities suffered by community members (Delgado, 2016). This observation brings a number of the factors discussed above to the fore once again: governmental and legal contexts create community marginalisation, while community organisation for community protocol processes is key to the expression or definition of a worldview. The Argentina case involves a community with a strong worldview transmitted through a history of struggle, and paid particular attention to inclusive organisation. By recording their worldview within a consultation procedure, this community is clearly seeking dialogue with external actors. Their community protocol is entitled 'tracks in the salt', where 'a track represents a path to follow' and the community protocol 'hopes to serve as a track, as a community conduit to channel our rights' (Comunidades indígenas de las Salinas Grandes y Laguna de Guayatayoc de Jujuy y Salta, 2015: 5). The South Africa case shows that communities of interest can also elaborate elements of a worldview, as the protocol communicates the links between spiritual beliefs, customary law, and the sustainable ways in which the practitioners harvest plants (Traditional Health Practitioners of Bushbuckridge, 2010: 2). The cases where no community protocol processes are underway support this point. The Greek and Malaysian cases both involve some community members feeling frustrated since they see others as misunderstanding their worldviews. Community protocols have some potential to facilitate dialogues between worldviews by ensuring these are communicated to those unaware of them at national and international levels, and because inclusive processes for drafting community protocols may allow worldviews to be developed, rediscovered and elaborated.

\section{External imposition of solutions}

The final theme to be discussued is external imposition. Though not a discourse per se, the dominant discourses guiding environmental governance assume the superiority of certain actors, and this translates into solutions being imposed by those actors. The potential role of community protocols in challenging external imposition is important, and allows for brief reflections on the remaining common feature of the cases: the role of supporting actors. All of the communities in the cases received support both from the NGO partnered with for research, and (with the exception of Greece) from other organisations. This bolsters the view that external support is often necessary for the elaboration of community protocols, and in turn raises issues. NGOs may be cast in the role of external imposer, foisting protocols on communities and ultimately compromising their ownership of the process and long-term empowerment. NGOs may also be seen as fulfilling roles that should instead be fulfilled by state institutions (Castree, 2008). In addition, the recognition of community protocols in the Nagoya Protocol may contribute to a perception of external imposition over time.

Beginning with the latter, the spaces unlocked by the international recognition of community protocols may be compromised if these instruments come to be imposed as a unique solution rather than promoted as one possibility among many. Here the tensions of global processes playing out at local levels are clear - the potential of community protocols has been argued to be closely linked to their authenticity as expressions of local values and practices. This authenticity requires that processes be driven by communities: if protocols are seen as imposed by institutions representing dominant discourses, they are unlikely to be embraced. The format of community protocols is also relevant here - written documents may not reflect the ways in which a given community reproduces and develops its practices, values, knowledge and so on. Though protocols may be recorded in various ways, to create dialogues they must be recorded in formats that can be understood by external actors. This may be an insurmountable obstacle for some communities and underlines one important limit of this instrument. In addition, the codification of community protocols may be seen to limit their ability to 
develop in dynamic ways, for example to adapt to changing political and legal contexts, a crucial element in their ability to challenge discourses (Robinson and Forsyth, 2016). The South Africa case suggests this, since the Kukula have been working towards amending their community protocol for some time.

On the role of NGOs and other organisations supporting community protocol processes, relevant points are raised by arguments about 'NGOization' (Choudry and Kapoor, 2013). Briefly, this line of argument highlights that NGOs can be seen as unwitting agents of neoliberalisation by fulfilling welfare roles instead of the state and, because they provide much needed services, robbing indigenous peoples' and other social movements of the will for the type of radical action necessary to challenge the dominant capitalist/colonialist discourse. The case studies here challenge this view, insofar as the NGOs engaged with the communities involved provided basic services. Instead, they provided support to navigate complex legal and policy landscapes. In addition, none of the cases concerned communities where social movements (understood as long-term struggles involving protest against an external actor or actors as opposed to community mobilisations directed at engaging with external actors) were underway. The exception is Argentina, where an indigenous movement has long existed. However, among the five cases studied the Argentina case saw the smallest roles for NGOs. All of the cases do suggest a relevant point about the role of NGOs in communities and funding. The sources of funding available to NGOs supporting community protocol processes is often project-based and shortterm, and sometimes dependant on demonstrative measurable outcomes. A mismatch between shortterm funding and the potentially lengthy processes leading to community protocols, (which do not yield immediate results), may compromise the efforts of NGOs. Thus, while NGOs are argued to affect the independence and range of actions of communities, NGOs are in turn often limited by the terms set by funders.

\section{Conclusions}

This article discussed the power dynamics of community protocols and ways in which they might challenge the dominant discourses that guide environmental law and policy at the local, national and international levels. Community protocols are seen as tools for achieving fair and equitable benefitsharing as well as (or perhaps because of) legal pluralism in environmental protection. Both are argued to have the potential to contribute to effective environmental protection and safeguarding human rights (Morgera, 2016; Tobin, 2013). The discussion drew on a comparison of 5 case studies and focused on three dominant discourses drawn from existing literature: colonialism/capitalism, the nature/culture divide and external imposition, with the latter two seen as flowing from the first. The discussion suggested that there is potential for community protocols to challenge dominant discourses, not least because the cases where community protocols were in place were those that secured some advances for the communities concerned. Community protocols may challenge dominant discourses by: facilitating and articulating the recognition of local communities and indigenous peoples; providing a source for understanding their worldviews; and by empowering them in the long term. Nevertheless, this potential to challenge dominant discourses is far from automatic. The case comparison highlighted the importance of the processes that lead to the development of community protocols: inclusive processes that do not simply assume an unproblematic community voice to exist emerged as important if community protocols are to address various arenas of power in an effective way. In addition, the discussion showed that community protocols must pay attention to four different areas that emerge from a comparison of the case studies: legal and political contexts; organisation; supporting actors; and the articulation of benefits. To exploit its potential, a community protocol must 
then strike a delicate balance between accommodating and being true to the voices of a community while exploiting and effectively addressing external actors and arenas. The value of community protocols is thus nuanced.

The four different areas identified suggest that future research should explore other bodies of literature to further unpack and define the conditions for community protocols in different locations and settings to be capable of challenging powerful discourses. Legal and political contexts matter where community protocols seek to enhance their ability to challenge powerful discourses. This may be a common sense finding, but it is one that is not explicitly discussed in the literature on protocols as legal tools. The literature on social movements suggests that a crucial determinant for campaign success is how far movements' respond to political and legal contexts (Meyer, 2004). How a community organises also emerged as critical to the power of community protocols in the case comparison, and ties in with the importance of recognition. For a community protocol to be an authentic reflection of a community's will, organisational forms must be inclusive and allow all sections of a community to be fully involved. The literature on deliberative democracy emerges as another useful point of reference for deepening these considerations, and deals with power relations within given groups and consensus-oriented processes (Habermas, 1985). How actors that support local communities should best fulfil their roles without compromising the community's ownership of the process or the community's long-term empowerment may also be usefully informed by literature on social movements and deliberative democracy, as well as more recent critical literature on global civil society (Choudry and Kapoor, 2013) that discusses the need for more radical engagement. The articulation of benefits, finally, emerges as important for communicating worldviews and defining benefits and thus a community's vision of development in ways that can provide detail to existing laws and policies. Again, this hinges on inclusive, consensus-oriented processes. A final unifying feature of all of these areas that should be pointed out is that they push us to a view of community protocols as processes rather than single events. To achieve their potential, the processes that lead to community protocols as well as their ability to evolve over time are paramount. In future work, I hope to bring these bodies of literature and considerations together to flesh out the preconditions for community protocols to effectively challenge power asymmetries. 


\section{References}

Adger, N. W., Benjaminsen, T. A., Brown, K., Svarstad, H., 2001. Advancing a political ecology of global environmental discourses. Development and Change 32 (4), 681-715.

Affolder, N., 2017. Non-state actors. In: Morgera, E., Razzaque, J. (Eds.) Encyclopedia of Environmental Law: Biodiversity and Nature Protection Law. Edward Elgar, Cheltenham, pp. 387398.

Bavikatte, S. K., 2014. Stewarding the Earth: Rethinking Property and the Emergence of Biocultural Rights. Oxford University Press, Oxford.

Bavikatte, S. K., Robinson, D. F., Oliva, M. J., 2015. Biocultural community protocols: dialogues on the space within. IK: Other Ways of Knowing 1 (2), 1-31.

Bixler, R. P., Dell'Angelo, J., Mfune, O., Roba, H., 2015. The political ecology of participatory conservation: institutions and discourse. Journal of Political Ecology 22, 165-182.

Brand, U., Vadrot, A. B. M., 2013. Epistemic selectivities and the valorisation of nature: the cases of the Nagoya protocol and the intergovernmental science-policy platform of the biodiversity and ecosystem services (IPBES). Law, Environment and Development Journal 9 (2), 202-220.

Castree, N., 2008. Neoliberalising nature: the logics of deregulation and reregulation. Environment and Planning 40 (1), 131-152.

Choudry, A., Kapoor, D., 2013. NGO-ization: Complicity, Contradictions and Prospects. Zed Books, London.

Comunidades indígenas de las Salinas Grandes y Laguna de Guayatayoc de Jujuy y Salta, 2015.

Kachi Yupi / Huellas de la Sal: Procedimiento de Consulta y Consentimiento Previo, Libre e Informado para las Comunidadades Indígenas de la Cuenca de Salinas Grandes y Laguna de Guayatayoc. https://cl.boell.org/sites/default/files/protocolo_final.pdf

Delgado, N. A., 2016. Community protocols as tools for resisting exclusion in global environmental governance. Revista de Administração de Empresas 56 (4), 395-410.

van Dooren, T., 2008. Inventing seed: the nature(s) of intellectual property in plants. Environment and Planning D: Society and Space 26 (4), 676-697.

Escobar, A., 1998. Whose knowledge, whose nature? Biodiversity, conservation and the political ecology of social movements. Journal of Political Ecology 5, 53-82.

Habermas, J., 1985. The Theory of Communicative Action Volumes 1 \& 2. Beacon Press, Boston.

Hayden, C., 2003. From market to market: bioprospecting's idioms of inclusion. American Ethnologist 30 (3), 359-371.

Greene, S., 2004. Indigenous people incorporated? Culture as politics, culture as property in pharmaceutical bioprospecting. Cultural Anthropology 45 (2), 211-237.

Jonas, H., Bavikatte K., Shrumm H., 2010. Community protocols and access and benefit sharing. Asian Biotechnology and Development Review 12 (3), 49-77. 
Jones, S., 2006. A political ecology of wildlife conservation in Africa. Review of African Political Economy 33 (109), 483-495.

Jukic, E., Collings, N., 2013. Community Protocols for Environmental Sustainability: A Guide for Policymakers. UNEP, Nairobi.

Koot, S. van Beek, W., Diemer, J., 2016. The Khwe of Namibia. Foragers between game, tourism and politics. Anthropos 111 (2), 497-511.

Laird, S. A., Wynberg, R. P., 2016. Locative responsible research and innovation within access and benefit sharing spaces of the Convention on Biological Diversity: the challenge of emerging technologies. Nanoethics 10 (2), 189-200.

Lukes, S., 2004. Power: A Radical View. Palgrave Macmillan, Basingstoke.

Marion Suiseeya, K. R., 2014. Negotiating the Nagoya protocol: indigenous demands for justice. Global Environmental Politics 14 (3), 102-124.

Mathevet, R., Peluso, N., Lee, N., Couespel, A., Robbins, P., 2015. Using historical political ecology to understand the present: water, reeds and biodiversity in the Camargue Biosphere Reserve, southern France. Ecology and Society 20 (4), 17. http://dx.doi.org/10.5751/es-07787-200417

Meyer, D. S., 2004. Protest and political opportunities. Annual Review of Sociology 30, 124-145.

Morgera, E., 2016. The need for an international legal concept of fair and equitable benefit-sharing. European Journal of International Law 27 (2), 353-383.

Morgera, E., Savaresi, A., 2013. A conceptual and legal perspective on the green economy. Review of European Community \& International Environmental Law 22 (1), 14-28.

Mulligan, S. P., 1999. For whose benefit? Limits to sharing in the bioprospecting 'regime'. Environmental Politics 8 (4), 35-65.

Nelson, F., 2010. Democratizing natural resource governance: searching for institutional change. In: Nelson, F. (Ed.), Community Rights, Conservation and Contested Land: The Politics of Natural Resource Governance in Africa. Earthscan, New York, pp. 310-333.

Oguamanam, C., 2012. Intellectual Property in Global Governance: A Development Question. Routledge, New York.

Parry, B., 2004, Trading the Genome: Investigating the Commodification of Bioinformation. Columbia University Press, New York.

Posey, D. A., 2004. Indigenous Knowledge and Ethics: A Darrell Posey reader. Routledge, Oxon.

Reimerson, E., 2013. Between nature and culture: exploring space for indigenous agency in the Convention on Biological Diversity. Environmental Politics 22 (6), 992-1009.

Ribot, J. C., Peluso, N. L., 2003. A theory of access. Rural Sociology 68 (2), 153-181.

Robinson, D. F., 2010. Confronting Biopiracy: Challenges, Cases and International Debates. Earthscan, London. 
Robinson, D. F., Forsyth, M., 2016. People, plants, place, and rules: the Nagoya Protocol in pacific island countries. Geographical Research 54 (3), 324-335.

Shiva, V., 1997. Biopiracy: The Plunder of Nature and Knowledge. South End Press, Cambridge, Massachusetts.

Sibuye, R., Uys, M.-T., Cocchiaro, G., Lorenzen, J., 2012. The Bushbuckridge BCP: Traditional Healers Organise for ABS in South Africa in Participatory Learning and Action, Biodiversity and Culture: Exploring Community Protocols, Rights and Consent. http://pubs.iied.org/pdfs/G03403.pdf.

Sikor, T. (Ed.), 2014. The Justices and Injustices of Ecosystem Services. Routledge, Oxon.

de Sousa Santos, B., 2015. Epistemologies of the South: Justice Against Epistemicide. Routledge, Oxon.

Svarstad, H., 2004. A global political ecology of bioprospecting. In: Paulson, S., Gezon, L. L. (Eds.), Political Ecology Across Spaces, Scales and Social Groups. Rutgers University Press, New Brunswick, pp. 239-256.

Tobin, B. M., 2013. Bridging the Nagoya compliance gap: the fundamental role of customary law in protection of indigenous peoples' resource and knowledge rights. Law, Environment and Development Journal 9 (2), 142-162.

Traditional Health Practitioners of Bushbuckridge, 2010. Biocultural Community Protocol of the Traditional Health Practitioners of Bushbuckridge. http://community-protocols.org/wpcontent/uploads/documents/South_Africa-Bushbuckridge_Biocultural_Protocol.pdf.

Uggla, Y., 2009. What is this thing called 'natural'? The nature-culture divide in climate change and biodiversity policy. Journal of Political Ecology 17, 79-91.

Vermeylen, S., 2007. Contextualizing 'fair' and 'equitable': the San's reflections on the hoodia benefit-sharing agreement. Local Environment 12 (4), 423-436.

Vermeylen, S., 2013. The Nagoya protocol and customary law: the paradox of narratives in the law. Law, Environment and Development Journal 9 (2), 185-201.

Vermeylen, S., 2017. Materiality and the ontological turn in the anthropocene: establishing a dialogue between law, anthropology and eco-philosophy. In: Kotzé, L. (Ed.), Law and Governance for the Anthropocene. Hart Publishing, Oxford, pp. 137-164.

Wilkinson, K., 2014. Payment for 'ecosystem services' and the 'green economy': green-washing or something new? Journal of Human Rights and the Environment 5 (2), 168-191.

Wynberg, R. and Hauck, M. (Eds.), 2014. Sharing Benefits from the Coast: Rights, Resources and Livelihoods. University of Cape Town Press, Cape Town. 